\title{
Case-Report: Cold and Confused
}

\author{
Karin Marieke Eggink and Maurice Vroegop \\ Radboud University Medical Centre, Nijmegen 6500, The Netherlands
}

Received: February 25, 2015 / Accepted: March 1, 2015 / Published: March 31, 2015.

\begin{abstract}
The authors describe the clinical presentation of a 59-year old woman in the emergency room, with agitation, confusion and hypothermia. She was previously diagnosed with hypothalamic-pituitary insufficiency with complete dysfunction of the pituitary gland, poikilothermia and central diabetes insipidus, treated with hormone supplements. In the emergency room, she showed a dysregulation in temperature, altered mental status and hyponatremia. The differential diagnosis was hypothermia based on infection with the history of poikilothermia, with dysregulation of her diabetes insipidus. Poikilothermia is an extremely rare condition in humans in which the body temperature variates with the surrounding temperature. Dysregulation may develop due to different causes.
\end{abstract}

Key words: Poikilothermia, hyponatremia, hypothermia, hypothalamic-pituitary insufficiency.

\section{Introduction}

Human beings are homeotherm and regulate their body temperature in accordance to surrounding temperature by peripheral vasodilatation, sweating, shivering and vasoconstriction. These mechanisms are regulated by the hypothalamus and are called thermal homeostasis [1]. When the hypothalamus fails poikilothermia develops. Poikilothermia is defined as the variation of body temperature with the surrounding temperature [2].

\section{Case}

The authors describe the presentation of a 59-year old woman, with agitation, confusion and hypothermia in the emergency room. After not been seen for a couple of days by her neighbour the patient was found in a confused and agitated state, unable to tell what happened. Prehospital a temperature reading was not possible with a normal thermometer. The patient had a history of hypothalamic-pituitary insufficiency, with complete dysfunction of the pituitary gland, poikilothermia and central diabetes insipidus, treated

\footnotetext{
Corresponding author: Karin Marieke Eggink, M.D., research field: emergency medicine. E-mail: k.m.eggink@hotmail.com.
}

with hormone supplements.

In the Emergency Room the patient showed GCS13, BP 125/80, pulse $90 \mathrm{bpm}$ in which an ECG showed atrial fibrillation and saturation $100 \%$ without oxygen. Temperature measured with deep rectal probe was $31.5{ }^{\circ} \mathrm{C}$. No apparent injuries, signs of infection or neurological problems were present. Laboratory results are shown in Table 1.

A chest X-ray showed no signs of pneumonia.

The differential diagnosis was hypothermia based on infection with the history of poikilothermia. Combined with hypernatremia based on decreased fluid intake and decreased mental state in central diabetes insipidus.

Patient was treated with intravenous antibiotics, hydrocortisone, desmopressin, warm glucose $5 \%$ fluids and a bearhugger.

After $6 \mathrm{~h}$ the sodium levels had decreased to 147 and the glucose $5 \%$ was switched to normal saline, temperature had risen to $35.6{ }^{\circ} \mathrm{C}$. The second ECG showed sinus bradycardia with no signs of ischemia. Despite increased temperature and decreased sodium levels, the patient turned from agitated and confused to lethargic and was variably responsive, GCS3-5-1. No other neurological symptoms were found. 
Table 1 Laboratory results.

\begin{tabular}{|l|l|}
\hline Sodium & 156 \\
\hline Potassium & 4.5 \\
\hline GFR & 50 \\
\hline WBC & 3.5 \\
\hline $\mathrm{CRP}$ & 15 \\
\hline Art gas: & \\
\hline $\mathrm{pH}$ & 7.32 \\
\hline $\mathrm{pO}_{2}$ & 9.0 \\
\hline $\mathrm{pCO}_{2}$ & 7.9 \\
\hline $\mathrm{HCO}_{3-}$ & 29.5 \\
\hline $\mathrm{BE}$ & 1.7 \\
\hline & \\
\hline Urine: & \\
\hline Osmolality & 159 \\
\hline Sodium & 39 \\
\hline
\end{tabular}

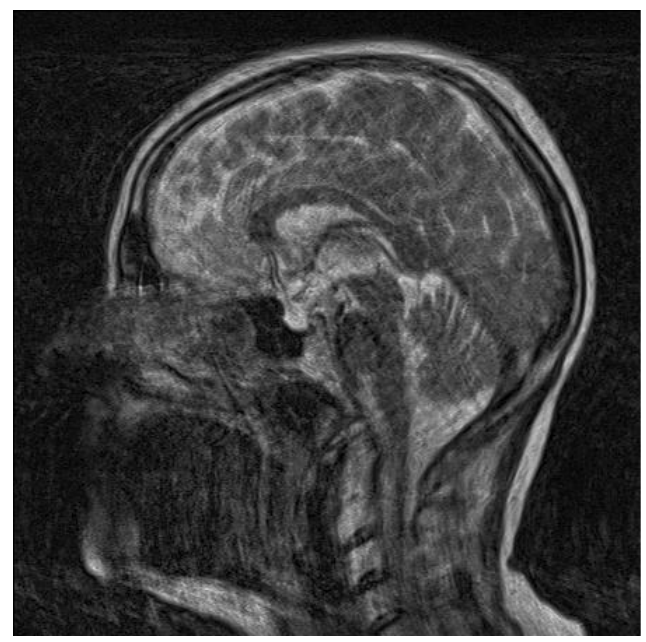

Fig. 1 Cerebral MRI with significant loss of pituitary tissue.
A cerebral CT and MRI were performed which excluded brain edema and other intracranial acute pathologies, and showed no signs of encephalopathy. Little pituitary tissue was seen with no anomalies in the hypothalamus (Fig. 1).

In the following days temperature and sodium levels stabilized with environmental temperature control, saline infusions, antibiotics, hydrocortison and desmopressin. The neurological status improved but she did develop delirium with hallucinations, which was treated symptomatically.

\section{Conclusion}

The hypernatremia and hypothermia in this patient were associated with her pre-existent hypothalamic-pituitary insufficiency with central diabetes insipidus. She probably developed a metabolic encephalopathy as a result of a secondary addisonian crisis, derailed diabetes insipidus or overly fast correction of the hypernatremia.

\section{References}

[1] Hermus, A., Pieters, G., and Burghouts, J. 1987. "Poikilothermia Klinische Les." Ned Tijdschr Geneeskd 131: 1745-7.

[2] Kurz, A., Sessler, D. I., Tayefeh, F., Goldberger, R. 1998. "Poikilothermia Syndrome." J. Intern. Med. 244 (5): 431-6. 